\title{
Mentoring teachers: An interview with Angi Malderez
}

\author{
Loreto Aliaga Salas \\ University of Leeds / RICELT
}

(Text received 21 July 2017; accepted 27 July 2017; final version 29 September 2018)

DOI: http://doi.org/10.5565/rev/jtl3.726

Dr Angi Malderez is a freelance education consultant, and Honorary Senior Fellow of the School of Education, University of Leeds, UK. Her work has been centred on supporting teacher learning and mentoring. She has worked in initial and continuous professional development for more than three decades in different countries around the world. She has co-authored Teaching teachers: Processes and practices with Martin Wedell, Mentor courses: A resource book for trainer-trainers with Caroline Bodoczky, and Navigating initial teacher training: Becoming a teacher with Andrew. J. Hobson and Louise Tracey, among others.

\section{Interview (June, 2017)}

Loreto: Can you tell us a little bit about you? How did you become interested in mentoring?

Angi: OK. Well, I think my interest has its roots in my experiences as a student teacher, really. But, formally, it began in the early 1990s. I think it was when I was in Budapest in Eotvos Lorand, the university there. We were setting up a new programme for teachers of English, we prepared teachers of English. And it was very privileged circumstances because we were sort of starting from scratch. It was immediately post-communism, politically we could start from scratch, and we were. We made it the aim of the programme that we wanted reflective practitioners, and it was an innovative programme. During the development of that programme, we realised that we were preparing people for a different profession, if you like, from the one we were engaged in. We were at the university, being academics and teachers of teachers and we were preparing people for schools, to teach English to children and young people in the state education system, so we knew that we wanted trainees to spend time in those schools, so we thought we would need collaborators in the schools to work with us. We called these collaborators initially co-trainers, we called them CoTs. We liked the idea of 'cots' because it was a good metaphor, it was a safe place for the 'baby' teachers to be nurtured if you like. And then we realised that it wasn't fair to identify willing teachers to help us without helping them be prepared for their role in helping us. So we started looking 
around and developing early mentor training if you like, programmes, and that was my job as outreach coordinator.

So that was the beginning of it all. That was the beginning. And we changed the name from CoTs to mentors because the more we read with this, for ideas of what we wanted, and how we might best support the teachers becoming mentors, becoming our co-trainers as we thought of them, the more we realised that actually they were what the other parts of the world were calling mentors. We took quite a lot from the early work of The Oxford Internship Scheme in the 80 s in the UK, and people were calling these people mentors, so that was the beginning, really, and it was so wonderful, that work. Working with those people was fabulous.

Loreto: So can you define mentoring in a nutshell?

Angi: Mentoring in a nutshell is the one-to-one support by a relatively more experienced teacher for the growth and learning of another, and for their integration into the school culture and the wider professional culture. It's my definition of mentoring. Currently, you know, you tweak it as you go along.

Loreto: Because there are different concepts, different jargon for mentoring. Recently we were talking about reflective practices, supporting teachers.

Angi: Well, for me a mentor has five roles. There is a lot of literature out there that talks about the roles of mentors, but for me a mentor has five roles. They are firstly to be a model, but not to be a model of good teaching because we all have to develop our own way of teaching, but to be a model of a reflective practitioner, and of a good teacher, a good professional (whatever 'good' means in any context), and to inspire. So that's the model role.

Then there is the acculturator role. There is the person who helps a new teacher into the culture of the school, or into the culture of the wider profession. Simple things in the school such as showing where the loos are, or you know, "don't sit in that chair because Mr. So and So sits on that chair". You know, ways to be in the school. But also ways to be in the profession, so the mentor may take the mentee along with them to local conferences, or go to a get-together of English teachers, or science teachers or whatever in the region. So the second role is being an acculturator, someone who helps somebody into the culture of the school and the wider profession. 
The third role is to be a support. Our own experience when we first starting teaching, as well as all the data from the Becoming a Teacher research project, underscores the fact that learning to teach, and beginning learning to teach in practice in schools, it's a hugely emotional roller-coastery kind of time, so a mentor role is to be a safe shoulder to cry on. A safe listener, and I say safe because as my friend and colleague professor Hobson would say, mentors must be ONSIDE (Hobson, 2016), which means, amongst other things, that the mentor cannot be also the line manager who makes judgements. That would render the relationship unsafe. The mentor mentee relationship is confidential. That's crucially important. Crucially important.

The fourth role, that's the sponsor role, and by sponsor I don't mean paying money for things, but it's about using the power that the mentor has, and I sort of mean knowledge as power actually, and connections with powerful people, in the service of the mentees, so it might mean something like the mentee needs some cards to make some visual aids, and the mentor knows the head teacher's got the cupboard with some card in it, you know, so goes and asks the head teacher for permission to take that, to give to the mentee. It's that kind of thing. Or it can also be putting them in contact with someone else that could help them better than the mentor can. "I know, I'm not very good at doing that, but I know someone who is. Let me introduce you", or "let me introduce you to this someone remotely, via what they've written". So it's using their power in the service of the mentee. That's the fourth role.

And the fifth role is the educator role. And for me the crucial component of this educator role is what in the English environment people call coaching, which it is, kind of, in the sense of what Elaine Cox writing about coaching defines as 'facilitated reflective practice'. So it is about coaching the mentee in their skills at becoming informed reflective practitioners, and that involves both developing, helping them develop their noticing skills, because you can't re-view, see again, something if you haven't seen it the first time, and so that's part of it. But there are also various steps, if you like, but there is a process of thinking, a systematic process, and it becomes a habit of thinking, so that is crucial in the educator role, you are, you are helping your mentee learn 'learnacy', what Claxton refers to as learnacy, and that is the ability to learn as a teacher. That's the main part of the educator role. It may also involve helping them learn specific little skills things, that come up as being as being needed, but mainly it's that 'ability to learn' that you practice.

You notice that I have not talked in any part of those roles about advising, or telling, because those are judgemental, they come from a place of a mentor acting on beliefs that they know what's right or better, or just knowing more and that would just undermine that whole 
aim: you cannot help your teacher learn learnacy if you are spoon-feeding ready-made judgement. They have to learn to make those informed judgements by themselves. You may, in your support role, it's not to say you never share what you know. Of course you do. And you may, for example do this in your support role. Let's say that the teacher is in a panic, you as mentor might say "Why don't you try this?", or "Here you are, try this", but that's not in educator role and is unhelpful when the mentee comes to rely on it, that's a fine judgement. Your main part of the educator role, your main duty under the educator is to support their learning of learnacy.

Loreto: I've never heard of learnacy.

Angi: Claxton (2004), I think, coined the term. You've heard the terms literacy and numeracy: abilities to read and write and to work with numbers. So learnacy is the ability to learn - teaching. That is arguably the main job of every kind of teacher, I'd say. Even more so for teachers themselves with all the changes in curricula and policies, and indeed the world they will need to adapt to over a career.

Loreto: So, I think you have answered my next question about why mentoring matters.

Angi: I hope I have. Yes, I think mentoring is crucial for lots of reasons. In terms of teacher learning, all the useful theories, things that they learn about in universities, or training courses, in workshops are pointless, even if they can regurgitate ideas in say, essays and exams, if they don't actually have a way of integrating them into their own thinking and practice. We used to call this the 'theory-practice gap'. Mentors can help mentees learn to make bridges. Some people, before they come in to learn to be teachers, somewhere in their educational journey, have developed the skill of learnacy, but an awful lot have not. And I remember Susan Barduhn, I think she used to be the president of IATEFL. She did her PhD on the CELTA and looked at whether or not people had learnt to reflect, and found, if I remember right, that it mattered whether they could already do it, if you like. It is not a given, you are not born with it. You need to be trained, or we need to be helped to learn how to do it, and not everybody can without that. Even if you can, you know, dutifully regurgitate on exams and tests what you've been told about, this ability, it's very different. And mentoring in the educator role can help, it's the only thing that can, can help someone combine all the types of knowledge a teacher needs and uses so that they have response-ability. You know a 
teacher's responsibility is his/her response-ability, meaning ability to respond to the learning needs of pupils.

Loreto: To put it into practice.

Angi: Except you don't put it into practice. You integrate it into your thinking, which changes your gut perception, and then it emerges into practice. It emerges into practice, rather than being put it into practice. There is no direct link between what you know about and what you do. It has to go via your experience. I explain this better in my 2007 book I think!

Loreto: Interesting change of approach.

Angi: Absolutely, and this is why it's so, in a way, it's so revolutionary in many cultures, where the predominant metaphor for teaching and learning is one of transmission.

Loreto: It's not knowledge transmission.

Angi: It's not knowledge transmission. You are using knowledge and you're thinking.

Loreto: It's a becoming.

Angi: It's a becoming. It's transformative learning. It's exactly that. It's Mezirow's idea of transformative learning. It is a becoming. And this is where the teacher identity. You know, one of my trainees, and this is a metaphor, this was years ago in Hungary, one of my trainees, her critical study at the end of her degree programme was on her developing as a teacher over the year that she had been teaching in school with the help of a mentor two days a week, or whatever they were, with the same class, for a whole year, with a mentor. And she said that her development as a teacher had been a bit like knitting a jumper. She had been given wool and knitting needles by the university and shown how to knit. Some of the wool had been dyed, but she had to make a jumper that suited her and fitted her, and fitted the climate of the class, and she was helped in her knitting by the mentor who would help her notice when she dropped a stitch. It was a fabulous, I can't remember the details of this final metaphor, but it is lovely. 
Loreto: Great, thank you.

Angi: You are welcome.

Loreto: You have mentioned some ideas about the role of the mentor, and the mentee in this dialogue. This permanent dialogue that they have. So what conditions do we need to make it effective and sustainable?

Angi: I refer to, it's not a cheap option. Too many governments have thought: wonderful, we will have mentors. They are cheap, they are in schools, they can just do it. Well, they can't. Conditions? An awful lot, actually. Mentors need sufficient and appropriate preparation and opportunities for on-going development because it is an act of teaching teachers, if you like, and I define teaching as supporting learning. So they need to understand something about how teachers learn, and as mentors, they need to learn the skills, some of the micro skills of helping teacher learning, such as post lesson discussions, how to manage those in a way that is supportive of the mentees learnacy development. They need to. OK, that's one thing. That has a cost implication.

Before that, mentors need to be hugely carefully selected. They should not be line managers because they need to be off line. The conversations with the mentees need to be confidential, so they should not be in any judging position. That is really complex because in many contexts they are also judges, but we've seen the negative impact that has had in our Becoming a Teacher and other research. We've seen how people don't want mentors because they think that other people would think that they are not good, and it's the opposite. Someone who actively seeks out a mentor is a really good teacher - someone who wants the opportunity to be continuously developing and knows that with a year or so of support that they will be able to do that. So, mentors need to be off line. In the selection process, mentors, before the mentor preparation at the very least, in most contexts, need to be recognised as probably as being, you know, good professionals, whatever that means, in any context, probably, for face validity. They need to have good interpersonal skills, and they need to have demonstrated some involvement in their own, some capability for their own learnacy, whether they articulate it like that or not, but they need to have been involved in improving themselves and recognise the value of that.

Then mentors need to be available to, and for, their mentees. A big part of being available is about time, they need to be given time to mentor. The whole issue of time and 
timetabling is important, and ideally within a school day, so that has timetabling implications for both mentor and mentee to be free, if you like, not teaching, not in classes, at the same time, so they can have their mentoring mentorials as I call them. That has cost implications as well. Mentors ideally need to be given some recognition. It may not need to be financial, it could be in terms of status if you like in recognition for the extra skill and work that they do. Both mentors and mentees ideally need to be willing, so they volunteer. So the title 'mentor' does not come as part of another role, automatically

Loreto: So mentors have to, ideally, would have to come from the same context.

Angi: Oh yes, ideally, yes. Yes, ideally. Very much so. Ideally from the same context. Having said that, in England Andy [Hobson] and colleagues have done some work about having external mentors, who are people not in the same schools, but of course, if you are not in the same school, you can't be an acculturator for the culture of the school. You can't take advantage of those quick conversations over the photocopier, or the coffee kettle, you know, the quick offload "What can I do?" support role opportunities, but given the atmosphere that we now have in England of judgementoring because people are telling them that is their job to advise, which it isn't, because advising comes from a position of knowing better, and it isn't that. It's knowing differently. We now have this situation where in some senses mentees feel freer to reveal their difficulties to external mentors. If you think you are going to be judged in terms of what you think your weaknesses are, you don't get the help you need. Whereas with external mentors, when this was instituted for science in the STEM subjects in England because there weren't chemistry teachers in a particular school, so it had to be an external mentor, those mentees felt free because their mentors were not involved themselves as a teachers in the internal politics of the school. So there are pros and cons.

Loreto: So in light of what you've just said, can you share some successful and maybe not that successful stories on mentoring that you have come across over the years?

Angi: Yes. Let me try and think. Successful. We had a project in Romania that was wonderful, actually, at a project level, if you like. It was managed by Sue Mace, an old colleague of mine. And it was a really, really good project. Cohorts of teachers that we trained, I don't quite like that word, sounds like dog, but who were given initial mentor preparation opportunities, they went off and mentored, and came back, had a conference 
about mentoring, where they shared their experiences and then some, who volunteered, came to Leeds and Caroline [Bodoczky] and I helped them prepare to be mentor trainers, so they took over, and they have run I don't know how many courses. They have set up a national mentor association, they speak to the policy makers, and mentoring is really quite embedded in Romania, which is great.

Loreto: Is it still running?

Angi: Yes.

Loreto: Brilliant.

Angi: And Doina Fleanta, my friend and colleague, is the president at the moment, and she runs mentor development programmes, and we have worked together in Rwanda, and she has been down to Chile.

Loreto: Brilliant.

Angi: She went to Kenya for me, when I couldn't go.

Loreto: There you go. And some not that successful?

Angi: Let me think about some not so successful. Well, mentoring in the UK. In England. It is not as successful as it needs to be. From our research, the causes are complex, but a main one was because quite clearly there wasn't sufficient mentor preparation or, I think, because mentor preparation consisted of, from what I have seen, from what I have heard, of a sort half day induction/which meant telling them when they have to fill the various bits of paper work.

Loreto: That is not mentoring.

Angi: Yes, there was no preparation for what it meant to do it, it was a kind of assumption because you are a teacher, you know how to teach teachers, and I was very sad to see that back in my country. That doesn't mean to say that mentoring has not been successful too, because people are people, sensitive and intelligent, you know, all the rest of it. But far too 
much judgementoring has gone on - understandably if you haven't been introduced to any alternative strategies and your own experience was of being judgementored. And mentors were, are, also required to be assessors, so it was, you know, the conditions were right for it to be less successful than it might have been as well.

Loreto: And that I guess that happens in different contexts where policy makers get involved.

Angi: Yes, exactly, it does. Policy makers have to be involved because there are cost implications. And we, as teachers of teachers in programmes that result in qualified teachers, have a responsibility too. But I think the argument goes, if they are going into classrooms anyway, which, by the way, I don't think a mentor needs to do at all - in fact it is easier for the mentor not to go into the classroom. I'll come back to that in a minute. But the argument of the policymakers' minds goes, if they are going into classes anyway, you know, they are the best placed to make the judgements too which saves us, you know.

Loreto: Similar to what OFSTED does.

Angi: Oh yes, well, yes, OFSTED is an inspectorate, but it is very different from what a mentor is doing. If the mentor is going into the classroom and is seeing things, and then asks the mentee, "So, tell me about the lesson", "Describe it to me". The mentee is going to think: "You are mad because you've been there, you've seen it". But that is not the point of that question, that starting point in a post-lesson discussion. The point of that question is to, over time, enable the mentee to notice more, because if you as a listener, as a mentor listener, can't make a clear picture in your head such as, say, Steve Spielberg would need in order to make a film of that class, then the mentee is not noticing as much as they could do, or perhaps would be helpful to their own learning and development of response-ability. For example, if you as a mentor are hearing them say, "Well, I went, and I did this, and I did that". In your mind as a mentor you are thinking, "Ah, my mentee is only noticing themselves, they are not telling me, they are not describing to me what the pupils are doing while they were doing those things". And if I, as a mentor, say, "Hang on a minute, I haven't got a clear picture. You said you did that, and what were the students doing then?" and then if the mentee says, "Well, these students were doing I don't know". Well, OK, you know. And if it is always the boys that the mentee notices, for example, the naughty ones, or the good ones, or whatever, you might need, in order to make that mental picture, to ask, "What about the girls? What about the slow 
ones? What about the ones at the back of the class? And what about...?". And by that questioning, and the mentee knowing that the mentor is going to be asking those kinds of questions, that the noticing of the mentee develops. So it makes mentoring easier NOT observing classes.

Loreto: Basically the role of the mentor here is just, not just, but it's a questioner, somebody that asks lots of questions, so the mentee is the one who reflects, who does the reflection by providing the right questions.

Angi: Yes, it is asking appropriate questions, and appropriate prompts. There are certain set steps in an informed reflection process where the mentor may have a more substantive sharing role, but it depends on the relationship, so I say may. Not if it is, you know, not too early on, and the rest of it, but it's, yes, so it is.

Loreto: I've seen in my context, in this new reform, one of the reforms that is being discussed at the moment is implementing a mentoring system for the whole country for newly qualified teachers of any subject. How? For so many newly qualified teachers of all the areas, all of the subjects?

Angi: Well, it is going to need, it is going to need work. We have it in England with the induction year, an induction year. It's called induction year. It's happening now. We have it in England. It's so-so successful. Could be better if there were more, and more appropriate, and possibly statutory, opportunities for mentor development, in my view.

Loreto: So it could be successful if they wanted to do it countrywide.

Angi: It could be, yes, it would require understanding about mentoring, and I know Doina was there doing something that I couldn't do in 2015.

Loreto: And what projects are currently working on?

Angi: I am being semi-retired at the moment, but the one, sort of the back burner is, one that I've resisted for ages, is a book about mentoring for mentors, for teachers becoming mentors. I think I will write it. I've sorted of started and paused at the minute. Just finished working on 
a project as consultant with Andy and other colleagues about mentoring in Kenya. Again piloted, whether that will be taken up or not, I don't know. Just finished this morning contributing to a book for mentor coordinators, not mentor trainers, mentor coordinators.

Loreto: And just a last question: how do you think, going back to public policies and decision makers, what is the role of mentoring in public educational policies?

Angi: I think it needs to be more central because without it, all the expense of training teachers is less useful. It can be wasted. We've got real problems in many parts of the world, teacher dropout, and that's a lot to do with what is been called 'reality shock' of coming all enthusiastic out of university and starting in a school and the reality of those horrendous first months and years even of being a teacher with no support. Our research shows that having an effective mentor, having support in the school, made a difference to whether or not people stay in the profession, and I should think all policy makers want those people who have trained, who are qualified to stay in the profession. First, we do have research that says mentors themselves learn, and gain renewed enthusiasm for teaching. Another crucial point of dropout is sort of burn out, fed-up mid-career collapse, but mentors get a new, I mean, a newer enthusiasm for that profession, so what did you ask me?

Loreto: About policies, public policies?

Angi: For me, teacher education, the learning of teachers typically is in two sites: if you like, the training room, the university lecture hall, whatever they do there and they should get their qualification, and the school. And whenever, at any time, a teacher, an early career teacher is in the school, there needs to be a mentor. The mentor doesn't have to know everything that comes from the university because in sytematic informed reflective practice, for example, in this version that I propose, the question a mentor would ask would be something like, "What else do you know about that? What did you learn at the university recently about that that may help you deciding which of those interpretations is right?". So you are prompting them to make the connection and close the infamous theory practice gap, if you like. And that habit of "I notice this", lots of possible ways of understanding this thing that I notice, "Do I make the decision? Hang on a minute, let me think what did I learn? What have I learned about this at university? Ah, yes, that might be it, so probably it is this, so what am I going to do". This habit of bringing ideas from others into your thinking as you are working on a very concrete 
instance of experience, instance of practice, is crucial for closing theory practice gap, and not wasting all the time that well-meaning people who devise wonderful programmes of study for future teachers have spent. But they are wonderful in the minds of those who give them. They won't become wonderful in the minds of the teachers until they see the relevance of them to their own practice. We are not always very good at supporting those processes of helping people see the relevance of things, and that's where mentoring can be crucial. So back to policies, mentors are or need to be central.

Loreto: How do you support the mentors?

Angi: We need to support the mentors through a phase of initial mentor preparation, and then networking opportunities between mentors, so mentors get together, on-going networking, you know, it can be electronically, WhatsApp things, meetings, or conferences, or whatever, yes. All these and other things that mentoring requires, such as the conditions. Don't put in impossible conditions of asking them to be a mentor and a judge. Give them time, get the timetabling right. Value them because it is demanding, and it requires them to learn more themselves in order to do the job. It requires them to give a lot for this demanding role, and it's a prestigious role. It should be.

Loreto: Is there anything else you would like to add? Concluding remarks?

Angi: Concluding remarks? Umm, to teachers thinking of volunteering as mentors, I'd say go for it. Be prepared to have to work hard to understand and practice your new role, but it will be so worth it. And to student and new teachers especially, but all teachers really, make sure you are given or find a mentor, preferably a suitably qualified one, to support you - it is not a sign of weakness but rather a sign of your strength and commitment.

Loreto: Thank you.

\section{Acknowledgments}

I would like to thank Dr Angi Malderez for her time and dedication to this interview. Also thanks to my PhD sponsor through CONICYT PAI/INDUSTRIA 72140460. 


\section{References}

Benton, P. (1990). The Oxford internship scheme: Integration+ partnership in initial teacher education. London: Calouste Gulbenkian Foundation.

Claxton, G. (2004). Learning is learnable (and we ought to teach it). In J. Cassell (ed.), Ten years on. The National Commission for Education report (pp. 237-250). Retrieved from

https://www.researchgate.net/publication/242101006_Learning_Is_Learnable_And_W e_Ought To_Teach_It

Cox, E. (2013). Coaching understood: A pragmatic inquiry into the coaching process. London: SAGE Publications. DOI: https://doi.org/10.4135/9781446270134

Hobson, A. J. (2016). Judgementoring and how to avert it: Introducing ONSIDE Mentoring for beginning teachers. International Journal of Mentoring and Coaching in Education, 5(2), 87-110. DOI: https://doi.org/10.1108/IJMCE-03-2016-0024

Hobson, A. J., \& Malderez, A. (2013). Judgementoring and other threats to realizing the potential of school-based mentoring in teacher education. International Journal of Mentoring and Coaching in Education, 2(2), 89-108. DOI: https://doi.org/10.1108/IJMCE-03-2013-0019

Hobson, A. J., Malderez, A., \& Tracey, L. (2009). Navigating initial teacher training: Becoming a teacher. Abingdon: Routledge. DOI: https://doi.org/10.4324/9781315787572

Malderez, A., \& Bodoczky, C. (1999). Mentor courses: A resource book for trainer-trainers. Camrbidge: Cambridge University Press.

Malderez, A., \& Wedell, M. (2007). Teaching teachers: Processes and practices. London: Bloomsbury Academic.

Mezirow, J. (1997). Transformative learning: Theory to practice. New Directions for Adult and Continuing Education, 1997(74), 5-12.

Wedell, M., \& Malderez, A. (2013). Understanding language classroom contexts: The starting point for change. London: Bloomsbury. DOI: https://doi.org/10.5040/9781472553287 


\section{Author information}

Loreto Aliaga Salas holds a $\mathrm{PhD}$ in Education from the University of Leeds. Her research focuses on teacher educators' cognitions in the context of a curriculum change in a pre-service language teacher education programme in Chile. She is a teacher of English, and has taught at primary, secondary, and in pre- and in-service teacher education in Chile and the UK. She is a founding member of RICELT, the Network of Chilean Researchers in ELT. ORCID ID: 0000-0003-4128-4161.

E-mail: loreto.aliaga.salas@gmail.com

To cite this article:

Aliaga Salas, L. (2018). Mentoring teachers: An interview with Angi Malderez. Bellaterra Journal of Teaching \& Learning Language \& Literature, 11(3), 109-122. DOI: http://doi.org/10.5565/rev/jt13.726 